\title{
Why Would Anyone Like To Share His Knowledge?
}

\author{
Vincent Homburg and Albert Meijer \\ Erasmus University Rotterdam \\ Faculty of Social Sciences \\ Center for Public Management \\ PO Box 1738 \\ NL3000DR Rotterdam, The Netherlands \\ E-mail: homburg@fsw.eur.nl, meijer@fsw.eur.nl
}

\begin{abstract}
Why do workers within organizations, or organizations in a network share information and knowledge? This question reverses the logic in some of the knowledge management literature, which addresses impediments and problems in information and knowledge sharing. According to property rights theory, information sharing can be explained in terms of self-interest, maximizing behavior, indispensability of groups and complementarity of assets. Based on this line of reasoning and on empirical evidence presented in this paper, we conclude that the ownership structure of information and knowledge systems matters. In building knowledge management systems, developers should take into account that the intuitive wisdom, indicating that central control is better control, should be interpreted with great caution.
\end{abstract}

\section{Introduction}

Nowadays, organizations are becoming more and more information-intensive. In many organizations, information and communication technologies (ICTs) are used to gather, process and disperse information. Often, so called "information repositories" are created for future reference $[1,2]$. Hospitals for example are using these to both register medical histories to support primary care processes and also to identify epidemiological trends and diagnosis-therapy-prognosis sequences. In commercial business environments, information repositories are an important impetus for organizational learning, product innovation and process innovation because they enable the detection of patterns, trends and so forth. Apart from these uses, in the public sector, information repositories are also used for the purpose of promoting political and legal accountability [3]. They are now sometimes defined as assets [4, 5, 6], indicating the 'resource' status that information has attained alongside the more traditional organizational resources. The crucial role that information has come to play in organizational life demands that it also be managed accordingly.

Bearing these considerations in mind, academics and practitioners have emphasized the notion of information and knowledge sharing in dealing with information repositories $[7,8]$. In fact, why would any organizational member not contribute to information repositories when this is obviously in the best interest of the organization as a whole? Information and knowledge is sometimes even shared by organizations at the level of organizational networks. In practice, however, several barriers to the creation and use of information repositories have been identified. In general skepticism about codification, currency, application and communicability of knowledge are often identified as factors which might explain why information and knowledge is not easily shared [9, 10].

In this paper we would like to elaborate on these questions regarding information and knowledge sharing. However, we do not focus on identifying barriers to the creation and use of information repositories but inversely ask what kind of incentives individuals in organizations or organizations in networks of organizations have (see also $[11,12])$ in contributing to information repositories. In other words, we ask ourselves the question why anybody would share her or his knowledge in the first place: which factors determine whether someone is willing to share his information with others, inside or outside the organization? This seems to be an important question for anyone concerned with the design and development of information repositories.

In the remainder of this paper, we follow Swan, Newell and Robertson [12] and present a theory driven, rather than a practice derived framework. In our case, the willingness and more specifically, the incentives of individuals and organizations to share information and knowledge, at both the organization and the interorganizational level, are respectively analyzed. More 
specifically, we use property rights theory $[4,5,6,13]$ to illustrate why self-interested individuals and organizations share (or: refuse to share) information and knowledge.

This paper is organized as follows. In section two, the research methodology is set out briefly. Section three describes the theoretical framework. Empirical data is presented in section four. In section five, results are summarized and discussed. This paper ends with conclusions and future research plans in section six.

\section{Research methodology}

The research objective of this study is to sharpen theoretical constructs in order to be able to contribute to the debate on information and knowledge sharing, both within and between organizations. This objective, loosely referred to as theory construction (rather than theory testing), indicates that the study has an exploratory character and therefore, considerable emphasis has been put on conceptual analysis of novel theories.

In order to confront initial explanations, propositions have been confronted with empirical data by means of two distinct strategies. Firstly, an exploratory expert consultation was undertaken in order to clarify empirical phenomena and to sharpen initial theoretical constructs. This consultation consisted of two consecutive e-mail questionnaires among an international panel of thirty experts in the field of electronic record keeping. In this questionnaire, the implications of using and introducing ICT-applications for the availability of information were addressed (for details, refer to [3]). In this study, the focus was on the level of individuals within an organization. The results of this consultation are presented in section 4.2.

The initial theoretical propositions, confronted with the outcomes of this Delphi-like expert consultation, were furthermore confronted with case study data that concerned information sharing of organizations in a network. The case study, which is described in detail in section 4.3, took place over a period of four months. In the study, data triangulation was emphasized and thus, data was gathered from several sources. Apart from analysis of policy documents, policy proposals and evaluation studies, fifteen semi-structured interviews with several stakeholders in a network of organizations were carried out.

The results of this study has given a rich, theoretically relevant picture of incentives with respect to information and knowledge sharing. It must be noted that, statistical generality has not been pursued. Therefore, the conclusions from this study are to be explored further and testable hypotheses are to be developed and tested in a real, live empirical setting. At this moment, however, we think that we have contributed to the process of theorizing about incentives, control of information and knowledge and knowledge sharing.

\section{Information, Control and Ownership}

\subsection{Introduction}

The increasing availability of information and knowledge, embedded in ICTs, gives rise to dilemmas with respect to the control over information repositories. Concerning these issues, two archetypical positions can be discerned:

- Central control over the information repository. This warrants central preservation and access to information. However, users may not be willing to contribute optimally to this repository since they do not bear any responsibility with respect to the repository.

- Decentral control over the information repository. When participants are responsible for their part of the repository they are assumed to be more willing to contribute to the repository. However, this may lead to fragmented, less easily accessible repository.

Popular wisdom in the knowledge management discipline states information and knowledge assets have to be centrally controlled, in such a way that ownership of information and knowledge coincides with the boundaries of the firm. In this situation, the organization's stockholders (or a department acting on behalf of them, such as an IS department) control and operate the information repository, and ultimately determine privileges (for usage, access, creation and modifying information and knowledge) since these privileges have not been explicitly granted to others. Van Alstyne, Brynjolfsson and Madnick refer to these privileges as residual right of control and illustrate this popular wisdom by stating that "(...) information systems designers often argue that central control is better control" [4, p. 267]. However, other scholars, like Killian and Wind, state with respect to information assets, that " (...) centralized ownership is often a second best, and indeed, occasionally the worst solution" [14, p. 274]. In order to clarify this controversy, it is necessary to analyze how ownership affects the functionality, profitability, and 
viability of information and knowledge assets [see also 13]. In order to do that, we first turn to property rights theory.

\subsection{Information Property Rights Theory}

A promising theoretical perspective which has been used to analyze governance and control with respect to assets is property rights theory $[6,15,16]$. Property rights are the rights to use (usus), reconstruct (abusus) and exploit (usus fructus) assets $[15 ; 16]$. The theory can be used to analyze governance mechanisms with respect to information assets and from the analysis, it is possible to show how information ownership in and between organizations affects the willingness to share information and knowledge.

The theory has a number of assumptions. The first assumption (A1) is concerned with bounded rationality, which in this case implies that property rights with respect to assets can never be completely regulated by means of contractual arrangements (e.g., designated rights). There will always be some contingencies that can not be anticipated beforehand, and hence, residual rights and residual claims (that is, ownership) are relevant. A special characteristic of ownership is that the rights not covered in a contract, reside with the owner; in other words, the owner is residual claimant. As we will elaborate later, this implies that owners always have more intensive incentives with respect to assets than nonowners.

The second assumption is that ownership of information and knowledge is not by definition assumed to accrue with the legal owners of an organization or a network of organizations (which in fact is true in a strictly formal, legal sense). Rather, but more realistically, various groups within the firm can be assumed to be the de facto owners with residual rights of control that can be transferred by changes in organizational structure or management edict (A2; see [4]). It is thus possible to identify two archetypes of asset ownership: concentrated ownership, in which ownership (residual rights) resides with one department in an organization or one organization in a network of organizations (cf. a central database), and dispersed ownership, in which departments in an organization or organizations in a network of organizations may exercise residual usus, abusus and usus fructus property rights with respect to the information and knowledge assets they are working with. In this situation, departments in organizations or organizations in a network of organizations may remodel data structures, employ different standards, et cetera as long as the minimally required forms of standardization that exchange of knowledge and information requires, are not violated (cf. a set of databases with a referral index).

The third assumption is that information and knowledge assets require at least some specific investments by organizational members working with them. This includes expertise, training and human capital. These investments are assumed to by typically noncontractible [13], and hence, not all costs that are incurred by information assets are fully verifiable. This means that they cannot be compensated directly (A3).

The key element with respect to assets in a property rights line of reasoning is self-interest: owners have a greater vested interest in information and knowledge assets than non-owners. This is so because owners of assets have access to designated and residual property rights, and are thus residual claimants. Therefore, owners can more fully appropriate benefits resulting from investment in assets than non-owners can. Inversely, this also means that owners have more intensive incentives to invest in assets and to adopt quality-enhancing or costsaving innovations than non-owners have. Non-owners also have the possibility to bargain for some of the surplus that results from their specific investments (eventually in the form of higher wages, promotions, or even more leisure time or on-the job consumption), but some of these benefits will always accrue to the owner in the bargaining process, mitigating the incentives of the non-owner. According to property rights theory, degraded incentives of non-owners gives rise to very subtle intangible costs of low effort. In the case of information this may occur through distorted, missing or unusable data [4], which eventually affects the viability of information and knowledge systems.

In order to analyze governance mechanisms and behavioral effects of ownership (i.c. ex-post bargaining), it is necessary to look at characteristics of the assets involved. In fact, property rights theory describes three situations: a 'standard' situation, a situation of complementary assets, and a situation of indispensable participants (departments or organizations)..

The incentives in standard situations can be described as follows. If self-interested employees are using and contributing to information and knowledge repository they don't own (e.g., can not fully exert property rights with respect to assets), these employees will try to be compensated for specific investments (for example, participation in on-the-job training programs). To do so, they have to bargain for extra wages, promotions, et cetera, with the owner of the assets. It can be expected 
that in this bargaining process, some of the (even nonmonetary) surplus that results from the specific investments accrues to the owner. This means that the employees face degraded incentives to participate in onthe-job training programs or any other forms of specific investments in the information and knowledge assets. This leads to subtle, intangible costs of low effort which may eventually result in distorted, missing, or unusable information submitted to central data bases, and, in general, in less viable information and knowledge systems. In this case, incentives for employees can be restored by changing the ownership structure in such a way that property rights are granted to the employees. In this case, one can imagine that various groups within an organization are using and building their own information and knowledge repositories that support them in the fulfillment of their tasks, and that a referral index is set up in order to enable a very minimal form of information and knowledge sharing. Although information and knowledge sharing by itself is in this situation less standardized and presumably more difficult, the incentives of the employees working with information and knowledge assets are more intense, their incentives to perform well and to use and contribute to information and knowledge assets, are restored. This decentralized ownership structure implies that groups of users can exert usus, abusus and usus fructus property rights and thus the incentive intensity and with that, the viability of the information and knowledge assets, increases. Note that such a situation contradicts the popular wisdom stating that centralized control is better control. In fact, the caricatural phrase 'a boss can tell a worker what to do' is replaced by the sentence 'rental cars are driven less carefully than cars driven by their owners'.

In the other situations property rights theory identifies, complementarity and indispensability, the bargaining process is somewhat different. Complementarity of assets refers to the situation in which knowledge assets only yield value when they are strictly used in conjunction with each other. If we take the example of a decentralized ownership structure with respect to information and knowledge systems, we see that surplus generated by means of specific investments by employees have to be compensated in a bargaining process involving employees and both the complementary assets' owners. Here, placing the complementary assets under central control (e.g., mitigating property rights) restores incentives because surplus has to be divided among less parties. An analogous line of reasoning also holds for the situation in which one of the groups in an organization (or one organization in a network of organizations) is indispensable (for a formal proof, refer to $[4,15 ; 16]$ ).

\subsection{Synopsis: Property Right Propositions}

Property rights theory, applied to information and knowledge assets, makes clear that the ownership structure matters. This is because ownership affects incentive intensity, and incentive intensity affects the viability of information assets through levels of specific investments. This is true for an organization consisting of a number of departments, as well as for organizations using ICTs to share information and knowledge in a network of organizations (by means of, for example, an interorganizational information system [6]). The key tenet of property rights theory is that:

- In the presence of strictly complementary information and knowledge assets and/or in the presence of indispensable groups or organizations in a network, usus, abusus and usus fructus property rights should be centralized.

- In all other situations, incentives (and with that, the viability of information and knowledge assets), can be improved by decentralizing property rights. Of course a decentralized ownership structure brings about disadvantages, but according to property rights theory, these disadvantages are compensated by the improved incentive intensity.

In order to illustrate the mechanisms of property rights, in the next section, empirical data is presented.

\section{Property Rights in Practice: Empirical Data}

\subsection{Introduction}

In order to investigate what importance ownership and control have with respect to information and knowledge assets, the property rights line of reasoning has been confronted with empirical data. In section 4.2, some results of an expert consultation are presented. These results illustrate some of the dilemmas that surround information sharing by individuals in an organization (for a detailed report on the results of this study, refer to [3]). This study gives information about the advantages and disadvantages of concentrated and dispersed ownership of information. In section 4.3, a case study of information and knowledge exchange by organizations in the Dutch 
sector of Higher Education and Research is used to illustrate the mechanisms of property rights theory.

\subsection{Information sharing by individuals in an organization}

In order to investigate the way organizations in practice deal with the ownership of information and knowledge assets, data from a consultation of thirty experts in the field of electronic record keeping were analyzed for tradeoffs and dilemma's with respect to the control of information and knowledge assets. In the study, several information and communication technologies are discerned. These are: e-mail systems, database management systems, generic software for creation of office documents, web technology systems and smart systems. The original study's objective was to clarify the experts' opinions on (1) what data should be kept and (2) how these data should be kept. In the context of the research objective mentioned in the introduction of this study, the latter question is of particular interest to us.

For the various investigated technologies from the expert consultation it is clear that there is a constant and real-existent practical dilemma between central and individual ownership. This is especially true for e-mail systems, office document software and web-technology systems. As one of the experts in the survey wrote: "The introduction of e-mail as a business communication tool has put the filing and control of e-mail-based correspondence exclusively in the hands of the individual users - and consequently the preservation of e-mail has become 'individualized' and unregulated". For database management systems and smart systems, these issues seemed less relevant to the experts in the consultation. They seem to assume that ownership over these systems is generally not under control of individuals.

A lack of central control may impede the retrieval of information (e.g. text documents and e-mail messages). However, central control may lead to what the experts referred to as de-contextualization. This refers to the situation in which information and knowledge is used for other purposes than originally envisaged, and the context of the business processes in which the information and knowledge was originally gathered, is lost. This means that there is opportunity for misinterpretation of the information.

Thus, the expert consultation did show that the use of ICTs can lead to questions concerning concentrated and dispersed ownership and highlights the relevance of ownership. Advantages and disadvantages of concentrated and dispersed ownership were brought forward. The consultation did not, however, shed light on workers' and asset owner's incentives to use and contribute to information and knowledge assets. Therefore, an additional study has been undertaken, a case study on the exchange of information in a network of organizations.

\subsection{Information sharing by organizations in a network}

In networks of cooperating organizations, ownership and control of information sometimes result in all kinds of ownership disputes, politicking, and so forth $[17,18,19]$. In general, this conflict can be analyzed as a conflict between the virtues of centralized, ubiquitous storage of data (in case of which diminished incentives of participating organizations eventually result in distorted, missing or incomplete data) and decentralized storage of data (in case of which information exchange is sometimes hampered because of incompatible data formats or data definitions).

The Dutch Higher Education and Research institutions provide an interesting example of dealing with information and knowledge assets in an interorganizational context. The field consists of a number of semi-autonomous institutions. Besides the Ministry, there are the universities and other research institutes, with their respective interest associations: the VSNU (Association of Dutch Universities) and the Royal Dutch Academy of Sciences- KNAW.

A special case within this context is the case of exchange of information on research activities. The case description will, from now on, focus on the exchange of information on research projects, which have been motivated by the wish to 'expose' current research activities to the academic and business communities. The information and knowledge assets involved are information systems embodying information on research projects carried out by universities and research institutes.

In 1988, in order to contribute to the goal of sharing and exposing of knowledge, plans were drafted to design and develop a central repository, the National Research Database (NOD). This was to be owned by a separate organization, the NBOI (the Netherlands Bureau of Research Information, later on renamed as NIWI, Netherlands Institute for Scientific Information). The development of the NOD system took a very long time. Eventually, in 1995, an information agreement was drafted stating that "research institutions have in principle agreed that they will submit research information to the NOD". As a result of this agreement, the NBOI assumed that the institutions were obliged to submit research 
information to the NOD. The institutions, on the other hand, assumed that an obligation existed only if there was not a single trace of doubt as to (1) the method of submission of information and (2) what organization should receive the information (e.g., to whom the NBOI should forward management information). The NOD criticized universities and their interest association over their poor provision of research information to the central repository at the NOD. In addition they wished to clarify who should be responsible for contributing to their costs for maintaining this repository. In fact, it was felt by the NBOI that the commitment of universities to the importance of 'exposure' of research activities by the NOD diminished because they did not experience any benefits from the NOD. In a meeting of the interest association of the universities, it is stated that "(...) the participating institutions are not fully convinced of the usefulness of the [NOD]. (...). [S]pecific partitions of the database, to be used by the universities for their own 'strategic' research policies, are not yet available (...). The academic institutes are apprehensive of putting research information, which is to be classified as 'strategic' and which consists of input and output data at specific aggregation levels, at the disposal of (potential) users without explicit permission. If it is not clear to what use the information is to be put, [the institutions] refuse to supply this information". The background of this point of view is clear from the following line of reasoning: "(...) if the NOD is accessible unconditionally, the Ministry is, through the back door, allowed access to information that, given the position of government, has to be characterized as 'management information'. Seen from the point of view of the universities, the supply of such an amount of management information is not acceptable". Although the participating institutions had agreed to contribute to and use the NOD, actual information and knowledge sharing by means of the NOD never met the objectives. During an Information Conference, it was noted that " $[\mathrm{t}]$ here is a problem concerning the filling of the NOD. Of fourteen universities, eight have a contract for electronic data interchange. By far not all research activities have been entered into the system (...)".

Gradually it became clear that the relatively centralized NOD system, owned by NBOI, could be classified as a failure. In the proceedings of another Information Conference, a representative of the institutions notes: "(...) from the reports, consults and interviews, it is clear that stakeholders prefer a coordinating and referring function with respect to research information systems. Therefore, no need exists for a complete, central and uniform register with detailed information with respect to output of research activities".

Following various meetings, the interest association of the universities, VSNU, starts to develop a new initiative, CombiSearch/CombiFormat, which technically resembles the NOD database, with one difference: it is explicitly acknowledged that the institutions 'own' the various decentralized information systems. A data model is developed by VSNU, but it can be adapted by the various participating institutions. During a short period of time, two competing initiatives for the collection of information on research activities emerged: the centralized NOD initiative, and the decentralized initiatives, also referred to as OIS/OZIS, by the institutions. As neither of the participating institutions nor NBOI had an interest in further fueling the debate between the competing knowledge management approaches of gathering research information, the NOD was gradually transformed into a referral system. The (new) NOD then, enables access from comparable information systems abroad (the report mentions the European CORDIS information system, the English CRIB database and the Belgian IWETO system).

After about 10 years of struggling, the owner of the centralized NOD admitted that "the alternative of decentralized data storage will predominate (...). [This implies] a changed role of the NOD, with a more important role for the decentralized input of data by the institutions who are responsible for the research activities. The role of NBOI/NIWI will change towards quality assurance and the active (international) marketing of the research information (...). In the long run the NBOI/NIWI database will consist of hyperlinks to the institutions' OZIS information".

\section{Summary of findings and discussion}

At the level of individuals in an organization the consultation of experts showed that the introduction of ICTs can lead to dilemmas concerning concentrated of dispersed ownership over information. Both have advantages and disadvantages. A lack of central control may impede the retrieval of documents and e-mail messages. However, central control may lead to decontextualization. This refers to the situation in which information and knowledge is used for other purposes than originally envisaged, and the context of the business processes in which the information and knowledge was originally gathered, is lost. This presents the opportunity for misinterpretation of the information.

At the level of organizations in a network the case of knowledge sharing by the participating institutions in the 
field of Dutch Higher Education and Research is a very sensitive subject. Over time, it has become clear that (1) the participating institutions' behavior in the network can be explained in terms of their self-interest and (2) that ownership of the research information is a very crucial concept. Firstly, as the property rights theory line of reasoning indicates, the institutions had very limited incentives to use and contribute to the NOD and consequently, the databases suffered from distorted and missing data. Secondly, because NBOI was residual claimant, the institutions also feared (and, later on, actively opposed) the position of NBOI. The reason for this was that NBOI, being 'owner' and residual claimant, was allowed to allocate residual rights of control with respect to the information and knowledge assets in a way which was very unfortunate for the participating institutions. NBOI's the residual rights of control allowed them to report to the Ministry about performance and other management information of the institutions. In short, the incentives of the participating institutions to use and contribute to the centralized NOD system were very weak.

The fact that a more decentralized system emerged provides support for the property rights theory line of reasoning. Just as property rights theory predicts, a decentralized ownership structure with the participating institutions acting as residual claimants, provided the institutions with more intensive incentives to perform. Furthermore, this ownership structure protected the institutions from unwanted interorganizational surveillance by NBOI.

As has been explained in the methodology section of this article, the research objective was to develop rather than to test theory. Therefore, the case study can not be used to actually corroborate or reject property rights theory. However, the case study data, in our opinion, provide at least some support for the usefulness of the constructs identified in property rights theory, such as 'ownership' of information and knowledge and residual property rights. In fact, the NOD indeed suffered from missing and distorted data, just as property rights theory's propositions stated. This problem, moreover, disappeared when the OIS system (with a basically different ownership structure) was implemented and obviously, incentives were restored. Nevertheless, both the property theory line of reasoning as well as the case study have serious limitations. First of all, the line of reasoning, including the depiction of employees acting completely out of selfinterest is of course a caricature (but perhaps not such an unrealistic one [20]). However, perhaps this view on workers and organizations participating in some sort of alliance or network is suitable to complement the sometimes very altruistic view on human beings and organizations which is adhered to in some parts of the knowledge management literature. Second property rights theory is not at all clear about the exact mechanisms that change the viability of assets as a result of a change in ownership structure. Property rights theory proposes very subtle mechanisms, which are not observable, but hypothesizes that eventually, they matter. Thirdly, property rights theory proposes an economic explanation of how ownership affects the behavior of people owning and/or using information and knowledge assets. However, from the case study, it should be clear that there definitely is also an organizational-political logic, indicating that organizations want to preserve their autonomy as much as possible [6]. In fact, one might conclude that the participating institutions are trying to prevent the 'decontextualization', which has been mentioned as a danger of central ownership in the expert consultation study. At this moment, property rights theory lacks a robust 'political' explanation. Studies by Orlikowski [18], Markus [17] and descriptions of the British Criminal Justice System and the Dutch Penal Law Enforcement Value Chain address such a 'political' explanation, albeit it is less formal and rigorous than a property rights theory explanation.

\section{Conclusions and future work}

In this study, the focus was on identifying why workers within organizations or organizations in an alliance or network of organizations share information and knowledge. This question, which is of course reflected in the title of the study, reverses some of the logic in the knowledge management literature, which addresses impediments and problems in information and knowledge sharing. We have used property rights theory to analyze information and knowledge sharing. This theory explains the behavior of individual organizational members and of organizations in alliances in terms of self-interest, maximizing behavior, and especially ownership structures. It hypotheses that human beings and organizations in alliances share information and knowledge when it is in their best interest. The question of when this is so is, among other things, determined by the ownership structure. The line of reasoning is that in the absence of complete contracts (e.g., assuming bounded rationality), and assuming no strict complementarity of assets or indispensability of actors, dispersed ownership of assets results in viable information and knowledge assets. The line of reasoning indicates that in this situation, incentives for organizational members or 
organizations cooperating in networks are intense and that this results in functional, profitable and viable information and knowledge assets and optimal conditions to share information and knowledge. This proposition was in fact acknowledged in the case study in which a change in ownership structure (from a concentrated ownership structure to a dispersed ownership structure) could be used to explain why the centrally organized NOD failed and the decentralized OIS system proved to be successful. Interesting in this case was that the same technology was used in both systems (e.g., standard data base technology), and the change in effects can be attributed to the change in ownership structure. This in fact confirms the statement of one IS practitioner, quoted by Davenport, Eccles and Prusak.: "No technology has yet been invented to convince unwilling managers to share information" $[19, \mathrm{p}$. 56].

The fundamental point here, of course, is thus that ownership of information and knowledge system matters. In building knowledge management systems, developers should take into account than the intuitive wisdom, indicating that central control is better control, should be interpreted with great caution. Rather developers and managers should look at characteristics of assets and groups in organizations or organizations in alliances in terms of complementarity of assets and indispensability of groups, and determine appropriate ownership structures. In the presence of strictly complementary information and knowledge assets and/or in the presence of indispensable groups or organizations in a network, usus, abusus and usus fructus property rights should be centralized and a central information repository is preferable. However, in all other situations, for some people counter-intuitively, incentives (and with that, the viability of information and knowledge assets), can be improved by decentralizing property rights and thus the design of an information system should be based on the idea of a federation of various information repositories. Of course a decentralized ownership structure brings about disadvantages, but according to property rights theory, these disadvantages are compensated by the improved incentive intensity. The basic lines of reasoning described in this study, however, should not be taken up as a cookbook. Ownership structures and decentralization of property rights provide complex problems (for example, organizational-political problems which, at this moment in time, are very hard to formalize), which have been explored only in a limited and exploratory way. Future research endeavors should try to define and operationalize more carefully the notions of residual property rights, ownership, complementarity of assets and indispensability of groups, and to test hypotheses in rich empirical settings. It is our conviction that the knowledge management community can benefit from these insights.

\section{References:}

[1] Scott Morton, M.S. (1991). The Corporation of the 1990s. New York: Oxford University Press.

[2] Croasdell, D., D. Paradice, J. Courtney. (1997). Using Adaptive Hypermedia to Support Organizational Memory and Learning. Proceedings of the Hawaii International Conference on System Sciences. Pp. 281-289. IEEE Press.

[3] Meijer, A. (1999). Consequences of the use of information and communication technologies for the availability of data for accountability. Second Round Delphi-survey. Available at: http://www.archief.nl/digiduur/cbieb.html

[4] Van Alstyne, M., E. Brynjolfsson, S. Madnick. (1995). Why not one big database? Principles for data ownership. Decision Support Systems. 15.pp.267-284.

[5] Brynjolfsson, E. (1994). Information Assets, Technology and Organization. Management Science. 40(12). pp. $1645-1662$.

[6] Homburg, V.M.F. (1999). The Political Economy of Information Management. (A Theoretical and Empirical Analysis of Decision Making regarding Interorganizational Information Systems). Groningen: University of Groningen, SOM.

[7] Nonaka, I, Takeuchi, T. (1995). The Knowledge Creating Company. New York [etc.] : Oxford University Press.

[8] Davenport, T.H., L. Prusak. (1998). Working knowledge: how organizations manage what they know. Boston, MA : Harvard Business School Press.

[9] Sherif, K., M. Mandiviwalla. (2000). Barriers to Actualizing Organizational Memories (Lessons from Industry). Proceedings of the 33rdHawaii International Conference on System Sciences.

[10] Hibbard, J., K.M. Carillo. (1998). Knowledge revolution. Informationweek. 5(663), 49-54.

[11] Pinker, E.J. R.L. VanHorn. (2000). Worker Incentives to Learn in Gatekeeper Systems: Lessons for the Implementation of Knowledge Management Systems. Proceedings of the $33^{\text {rd }}$ Hawaii International Conference on System Sciences. 
[12] Swan, J., S. Newell, M. Robertson (2000). Knowledge Management: When will People Management Enter the Debate? Proceedings of the $33^{\text {rd }}$ Hawail International Conference on System Sciences.

[13] Bakos, J.Y., B. Nault. (1997). Ownership and Investment in Electronic Networks. Information System Research. pp. 321-341.

[14] Killian W., M. Wind. (1998). Changes in Interorganizational Coordination and Cooperation. In: Snellen, I.Th.M., W.B.H.J. van de Donk. Public Administration in an Information Age. Amsterdam: IOS Press. pp. 273-291.

[15] Grossman, S., O. Hart (1986). The Costs and Benefits of Ownership: A Theory of Verticaland Lateral Integration. Journal of Political Economy. 24(4). pp. 691-719.
[16] Hart, O., J. Moore. (1990). Property Rights and the Nature of the Firm. Journal of Political Economy. 98(6). pp. 1119-1158.

[17] Markus, M.L. (1983). Politics and MIS Implementation. Communications of the ACM. pp.430-440.

[18] Orlikowski, W. (1992). Learning from Notes: Organizational Issues in Groupware Implementation. In: Proceedings of the CSCW. Toronto: ACM.

[19] Davenport, T.H., R.G. Eccles, L. Prusak. (1992). Information Politics. Sloan Management Review. Fall. pp. 53-65.

[20] Hart, O. (1995). An Economist Perspective on the Theory of the Firm, In: O.E. Williamson.Organization Theory: From Chester Barnard to the Present and Beyond. Oxford: Oxford University Press. 